\title{
Oscillations in Drifts of Auroral Patches
}

\author{
Takasi Oguti, Rumi NAKAmURA, and Tatsundo YAMAmoto \\ Geophysics Research Laboratory, University of Tokyo, Tokyo, Japan
}

(Received June 11, 1987; Revised August 3, 1987)

\begin{abstract}
On the basis of all-sky TV records of auroras, faint auroral patches (nonpulsating in luminosity) are found to oscillatorily drift associated with concurrent magnetic pulsations on the ground. These oscillations in the drifts of auroral patches are found to be consistent with the oscillations in the electrostatic electric field associated with the concurrent magnetic pulsations. This implies that these magnetic pulsations are brought forth by ionospheric electric currents which are produced by electrostatic electric fields associated with shear Alfven waves in the magnetosphere. The result, therefore, indicates that the simultaneous measurement of the drifts of auroral structures at the time of ground magnetic pulsations is a convenient method of examining whether the magnetic pulsations are really ascribed to $\mathrm{HM}$ wave fields propagating down from the magnetosphere, or if they are essentially caused by the change in conductivity inhomogeneity in the ionosphere. It is also shown that the azimuthal phase speed (wave length), as well as the oscillation amplitude, highly varies from the dayside to the evening, i.e., it is larger in the dayside and becomes much smaller toward the evening sectors. Theory must take this steep longitudinal non-uniformity into consideration.
\end{abstract}

\section{Introduction}

Faint auroral patches (non-pulsating in luminosity) were seen above La Ronge, Saskatchewan, Canada, in the evening on February 17, 1980 during the period of the joint University of Tokyo-University of British Columbia Aurora-ULF-VLF campaign, coordinated with the Canadian Pulsating Aurora Campaign (MCEwEN and DUNCAN, 1981). The magnetic condition of the day was rather quiet after large activity $\left(K p_{\max }=6\right)$ on the previous day. The auroral patches were found to oscillate predominantly in the east-west direction with a period of 10 minutes concurrently with the magnetic pulsations of the same period that occurred in the auroral zone.

Auroral patches are most likely projections of cold plasma irregularities in the distant magnetosphere where energetic electrons are scattered and precipitate to the auroral altitude (OGUTI, 1976; JOHNSTONE, 1983). This is possibly valid not only for the pulsating auroral patches but also for non-pulsating (in luminosity) patches. The drifts, therefore, are most likely due to electric fields (OGUTI, 1981; SCOURFIELD et al., 1983; NAKAMURA and OGUTI, 1987). The oscillations in drifts of the auroral patches could indicate the oscillations in electric fields associated with magnetic pulsations. 
Magnetic field fluctuations on the ground are produced by the fluctuations of the ionospheric electric currents. The current fluctuations are due to fluctuations both in the ionospheric electric fields and in the conductivity. If the conductivity is spatially uniform and temporarily constant, then the fluctuation of the current is directly related to that of the electric fields, but, if the conductivity spatially and temporarily changes, then the current fluctuations are induced even when the background electric field is stationary and uniform. The latter is the case for PiC magnetic pulsations which occur below pulsating auroras (OGUTI and HAYASHI, 1984, 1985; OGUTI, 1986). On the other hand, magnetic pulsations in this study are most likely ascribed to the electric field variations under the condition of a uniform conductivity, because the auroral patches here are extremely faint, and hence, no significant modulation is expected to occur in the ionospheric conductivity.

In order to examine whether the oscillatory drifts of the auroral patches are really consistent with the changes in electric field associated with magnetic pulsations, and to further examine the properties of the oscillations of the auroral patches and concurrent magnetic pulsations, the relationships between them are studied in this paper.

\section{Data and Analysis}

The data used in this study are all-sky TV records of auroras obtained at La Ronge, ordinary magnetograms at 22 stations mainly in the Canada-Alaska area and induction magnetograms from Rabbit Lake (RBL) and La Ronge (LRG) below the oscillating auroral patches from 02:59 to 03:25 UT on February 17, 1980. Magnetic field variations at GOES-3 satellite are also examined. Lists of the stations as well as the coordinates are given in Table 1.

The luminosities of the auroral patches are sampled from the video signals at 240 points both along the meridian lines and along the east-west lines. The spatial separation of the sampling point along each line is approximately $1.7 \mathrm{~km}$ at the auroral altitude $(100 \mathrm{~km})$, and hence, each array covers approximately $400 \mathrm{~km}$ to the east-west or north-south extent. Then, the luminosities, thus sampled, are plotted in the position-time displays. Figure 1 shows an example of the position-time displays of the auroral patches along with indications of the sampling arrays on the all-sky frame (all-sky picture in the lefthand side). The top through the 5th rows are the displays along the east-west lines, passing $140 \mathrm{~km}$ and $100 \mathrm{~km}$ north of the zenith, the zenith, and $100 \mathrm{~km}$ and $200 \mathrm{~km}$ south of the zenith. The arrays here are arranged such that they cover from $100 \mathrm{~km}$ east to $300 \mathrm{~km}$ west since auroral patches are absent further east. Auroral luminosity is represented by the darkness. The dark streaks which go up with time indicate the eastward drifts of the auroral patches and those going down represent the westward drifts. The tangent of these streaks gives the drift velocity in the east-west direction.

The figure shows that the general drift is westward in whole the observation range for the time interval, being natural for the local time (approximately from 18:30 to $21: 00 \mathrm{MLT})$ of day at this latitude $\left(64.9^{\circ}\right.$ in geomagnetic latitude). The average drift 
Table 1.

\begin{tabular}{|c|c|c|c|c|c|}
\hline \multirow{2}{*}{ Station } & \multirow[t]{2}{*}{ Abbr. } & \multicolumn{2}{|c|}{ Geographic } & \multicolumn{2}{|c|}{ Corrected Geomagnetic } \\
\hline & & Lat. & Long. & Lat. & Long. \\
\hline Sachs Harbour & SAH & 72.0 & -125.8 & 75.2 & 265.9 \\
\hline Inuvik & INK & 68.3 & -133.3 & 70.6 & 266.2 \\
\hline Arctic Village & AVI & 68.1 & -145.6 & 68.1 & 255.3 \\
\hline Fort Yukon & FYU & 66.6 & -145.3 & 66.8 & 257.7 \\
\hline College & $\mathrm{COL}$ & 64.9 & -148.1 & 64.8 & 257.1 \\
\hline Talkeetna & TLK & 63.3 & -150.1 & 62.9 & 256.8 \\
\hline Cambridge Bay & $\mathrm{CBB}$ & 69.1 & -105.0 & 76.8 & 298.3 \\
\hline Yellow Knife & YLK & 62.5 & -114.5 & 70.0 & 294.2 \\
\hline Norman Wells & NOW & 65.3 & -126.8 & 69.4 & 276.9 \\
\hline Fort Simpson & FSP & 61.8 & -121.2 & 67.2 & 287.2 \\
\hline Sitka & STK & 57.1 & -135.3 & 60.3 & 277.7 \\
\hline Baker Lake & BKL & 64.2 & -96.0 & 75.1 & 320.4 \\
\hline Rabbit Lake & $\mathrm{RBL}$ & 58.2 & -103.7 & 68.1 & 311.9 \\
\hline Lynn Lake & LYN & 56.9 & -101.1 & 66.0 & 315.8 \\
\hline La Ronge & LRG & 55.2 & -105.3 & 64.8 & 311.0 \\
\hline Meanook & MNK & 54.6 & -113.3 & 62.0 & 303.6 \\
\hline Rankin Inlet & RIT & 62.8 & -92.2 & 74.3 & 328.0 \\
\hline Churchill & $\mathrm{CHR}$ & 58.7 & -94.1 & 70.2 & 326.0 \\
\hline Gillam & GIM & 56.4 & -94.4 & 68.0 & 326.3 \\
\hline Island Lake & ISL & 53.9 & -94.7 & 65.5 & 326.5 \\
\hline White Shell & WHS & 49.8 & -95.2 & 59.7 & 328.0 \\
\hline Great Whale River & GWR & 55.3 & -75.5 & 67.9 & 357.6 \\
\hline Ottawa & OTT & 45.4 & -75.6 & 56.6 & 353.9 \\
\hline Memambetsu & MEM & 43.9 & 144.2 & 37.4 & 213.7 \\
\hline
\end{tabular}

speed prior to the oscillations is as slow as $20 \mathrm{~m} / \mathrm{s}$. The slow westward drift is overlapped with oscillatory movements, studied in this paper, from 02:59 to 03:25 UT. The period of the oscillation is about 10 minutes. The maximum double amplitude about $100 \mathrm{~km}$ and the maximum speed about $400 \mathrm{~m} / \mathrm{s}$ (see also Figs. 2 and 3) are obtained at the northwesternmost part of the observation region, i.e., $300 \mathrm{~km}$ west along the $140 \mathrm{~km}$ north array, from 03:00 to 03:10 UT. The oscillatory movements of the auroral patches are not inphase in the all-sky, but spatially varies. On a certain latitude, the phase leads in the more western parts (more dayside) and lags in the more eastern parts (more nightside) as shown by a slant line on the second row from 03:03 to 03:06 UT. Similarly, the phase leads in the lower latitude and lags in the higher latitude as inferred by comparing the eastward oscillation at 03:03 UT on the fourth row (100 km south along the meridian) with that at 03:05 UT on the second row (100 $\mathrm{km}$ north along the meridian). These oscillation characteristics will be examined in the next section. 


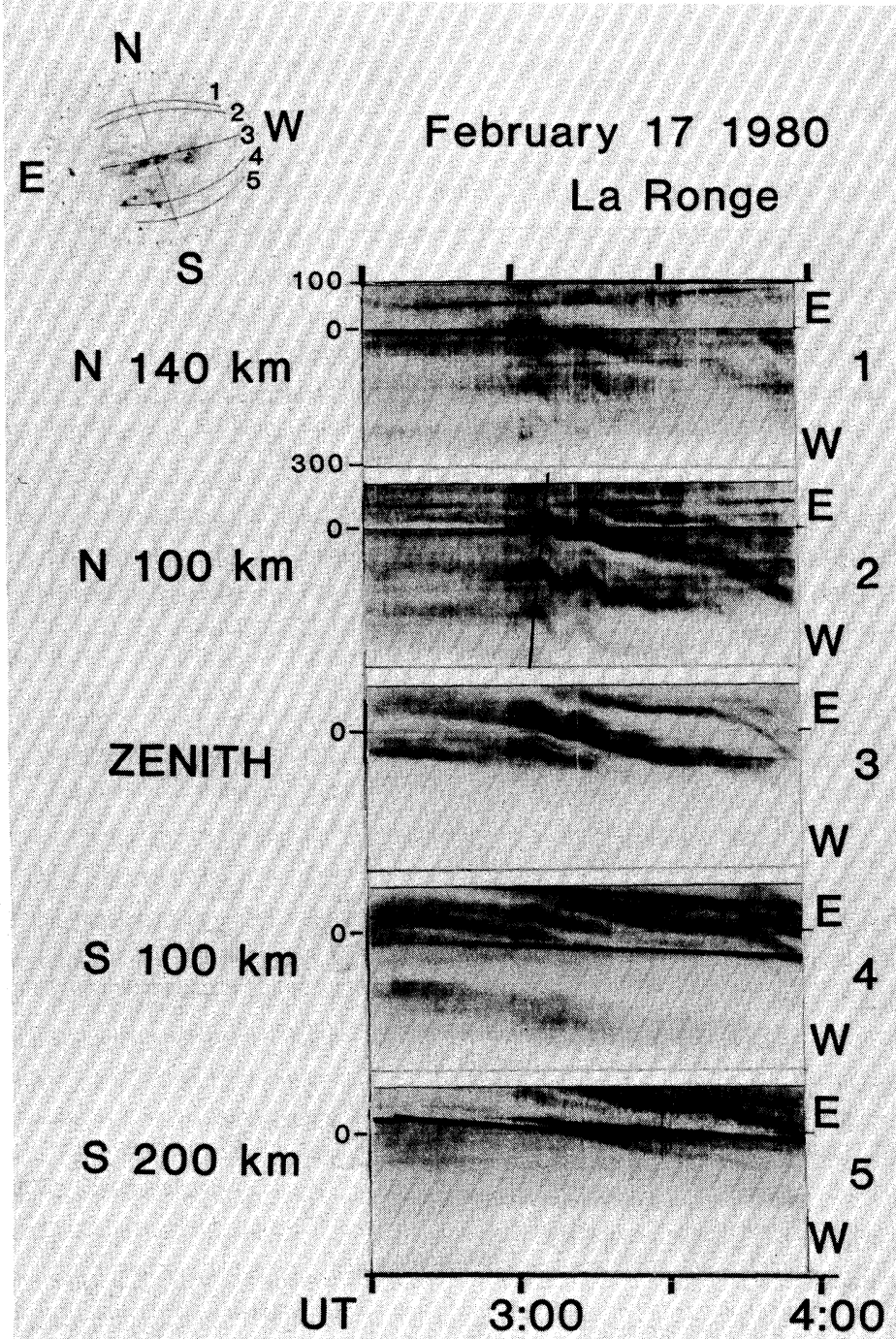

Fig. 1. An example of a position-time display of auroral patches above La Ronge along the magnetic east-west lines (02:30-03:56 UT, February 17, 1980). From the top to the bottom, the selected lines pass $140 \mathrm{~km}$ and $100 \mathrm{~km}$ north, the zenith, and $100 \mathrm{~km}$ and $200 \mathrm{~km}$ south of La Ronge. The upper and the lower boundaries of each row are $100 \mathrm{~km}$ east and $300 \mathrm{~km}$ west of La Ronge magnetic meridian, respectively. The dark streaks going up or down with time indicate the eastward or westward drifts of auroral patches. 
Drifts of Ruroral Patches above La Ronge

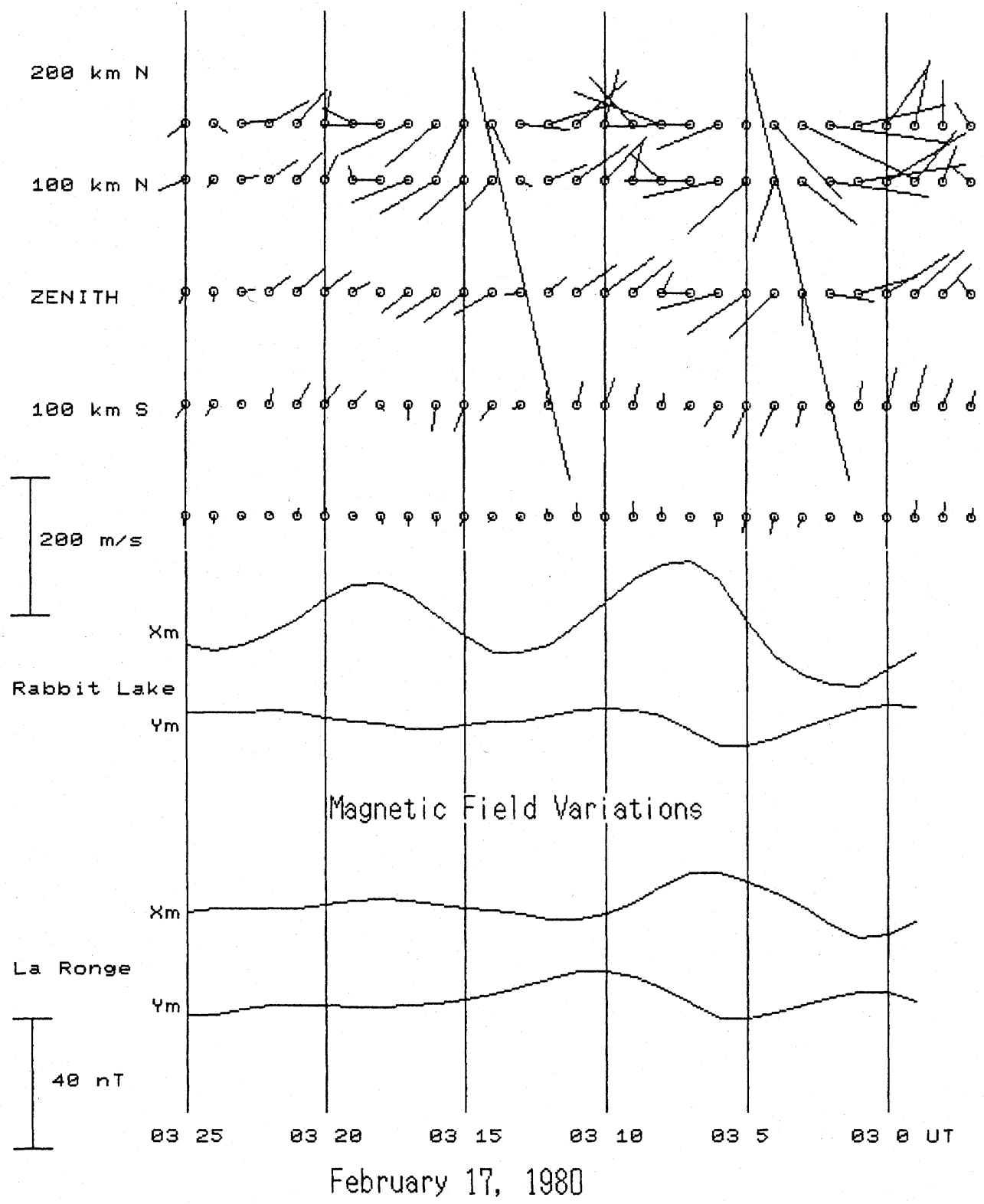

Fig. 2. A meridian-time display of the drifts of auroral patches above La Ronge (top panel) along with concurrent magnetic pulsations at Rabbit Lake and La Ronge (bottom panel). Rabbit Lake is located approximately $300 \mathrm{~km}$ north of La Ronge. Time is from the right to the left. 

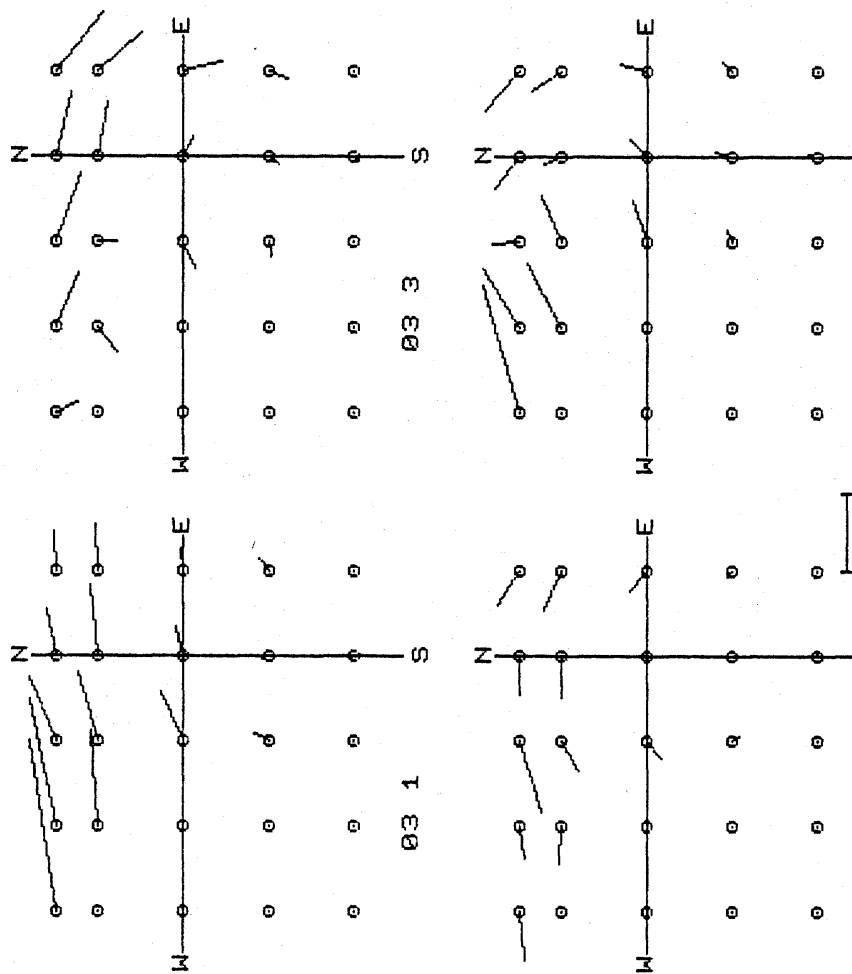

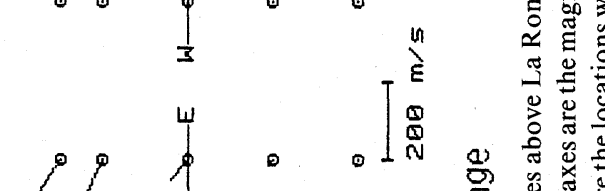
Q) 8

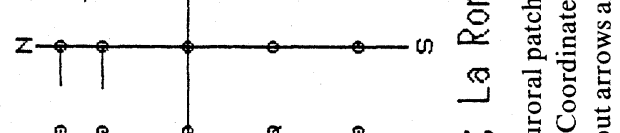

记

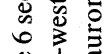
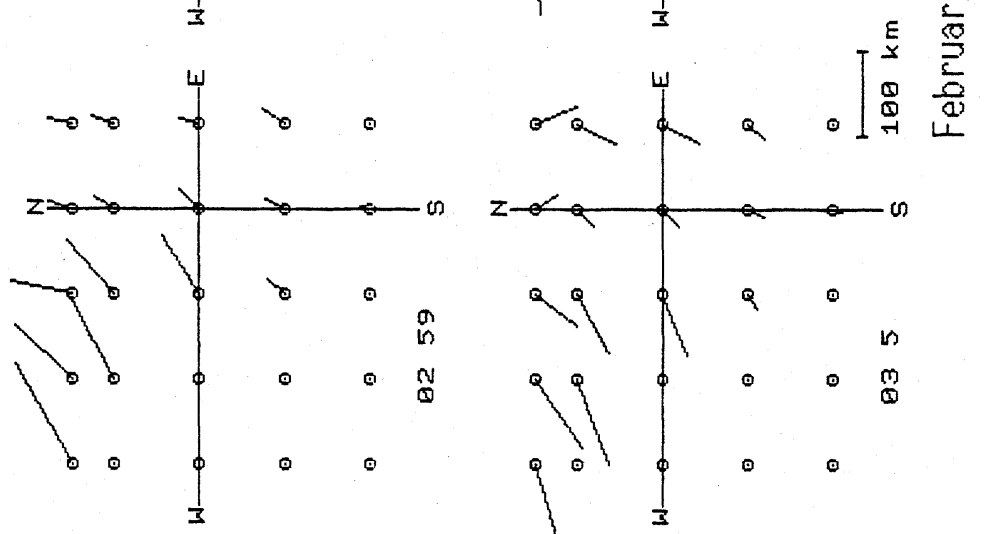


\section{Temporal-Spatial Variations of the Oscillatory Drifts}

Two-dimensional distributions of the drift velocities are first obtained by combining the north-south and the east-west components of the drifts on the basis of the expressions similar to Fig. 1. The velocity is obtained at the grid points, with a spatial separation of 100 or $50 \mathrm{~km}$ in the ionospheric coordinates, where the auroral patch is available in its vicinity. Then, the drifts along three geomagnetic meridians, i.e., passing $100 \mathrm{~km}$ east, zenith and $100 \mathrm{~km}$ west of La Ronge, are averaged at each latitude, and plotted in a latitude-time display in Fig. 2. This expression is substantially identical to that which is often used in the representation of radar drifts by means of the fixed meridian mode (e.g. WALKER et al., 1979; VILLAIN, 1982). The time, here, is from the right to the left. The reason for this is that the figure could represent the two dimensional spatial distribution of the vectors if the change in the vectors result from the uniform propagation of waves.

The poleward phase shift with time is evident in this figure with a phase speed of about $1.5 \mathrm{~km} / \mathrm{sec}$ as indicated with slant lines. This is approximately equal to the poleward propagation of the phase in drifts obtained earlier by the STARE radar during Pc5 magnetic pulsations in the evening sectors (WALKER et al., 1979; VILLAIN, 1982). Figure 2 also shows concurrent magnetic pulsations at La Ronge and Rabbit Lake (approximately $300 \mathrm{~km}$ north of La Ronge) which were originally obtained by induction magnetometers and time-integrated. The relationships between the drift oscillations and the magnetic pulsations will be examined later in detail.

Figure 2, although convenient to see the poleward phase propagation, does not really indicate the two dimensional distribution of the drift vectors, which is crucial in examining the oscillation characteristics, especially in the longitudinal (azimuthal in the magnetosphere) direction. Subsequently, the two-dimensional distribution of the drift velocity is examined every one minute. Six examples of the drift distribution are shown in Fig. 3 as viewed from the above. The time interval of each figure here is 2 minutes. Hence, these six examples cover approximately one cycle of the oscillations. The points without velocity vectors are the locations where the auroral patches are not available. As seen in the figure, the velocity is larger in the western and the northern parts, and the velocity vector rotates clockwise. It is evident that the phase of the oscillation advances in the lower latitudes and western (more dayside) region and lags in the higher latitudes and in the eastern (more nightside) region. The azimuthal phase speed from the dayside to the nightside is $3-4 \mathrm{~km} / \mathrm{sec}$ along the east-west lines $100 \mathrm{~km}$ and $140 \mathrm{~km}$ north of La Ronge. Thus, 10 -minute time span (period of the oscillation) of Fig. 2 is equivalent to the azimuthal wave length of approximately $2000 \mathrm{~km}$ in the east-west direction and results $7-8$ in the conventional azimuthal wave number if determined in this area.

Note that the oscillation amplitude shows a large longitude-dependence in this figure; larger in the more dayside. Furthermore, the oscillation is predominantly azimuthal (in the east-west direction) in the north-western (more dayside) region while fairly radial (in the north-south direction) especially in the late evening hours, 
i.e., $100 \mathrm{~km}$ east of La Ronge and possibly in the further east. We like to emphasize the importance of the longitudinal non-uniformity of the oscillation, although many earlier studies are mostly concentrated on the temporal variations along a single meridian line in studying the phase characteristics of the pulsations in the north-south direction. The oscillations here are not uniform at all in the longitudinal (azimuthal) direction.

This indicates that the conventional translation of the temporal change of the drift along a certain meridian into the spatial distribution (equivalent of regarding Fig. 2 as the spatial structure) is not really valid. This also raises some question about the validity of the assumption that the wave is stationary in the azimuthal direction in estimating the wave characteristics such as the azimuthal wave number. This will be further discussed later in relation to the concurrent magnetic pulsations.

\section{Relationships between Drift Oscillations and Magnetic Pulsations}

Based upon the spatial distribution and its temporal variation of the drifts obtained every minute, the relationships between the drifts of the auroral patches and magnetic pulsations, measured below the oscillating auroral patches, are examined. Figure 4 shows hodograms of the drift velocity (lefthand side) and that deduced from

AURORAL DRIFT

VELOCITY

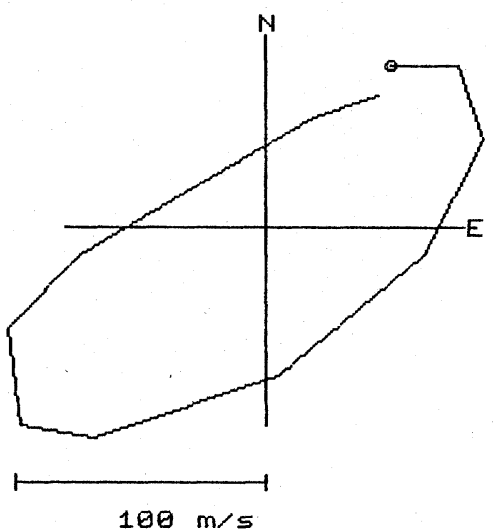

DRIFT DEDUCED

FROM

MAGNETIC PULSATION

\section{9-0310 UT, FEB. 17, 1980, La Ronge}

Fig. 4. Hodogram of the observed drift velocity of auroral patches (left) and that of the drift deduced from the magnetic pulsations (right) from 02:59 to 03:10 UT, February 17, 1980 at La Ronge. The observed drifts are averaged in an area $\pm 100 \mathrm{~km}$ both in north-south and east-west directions centered at La Ronge. The deduced drifts are the vectors reversed from the expected currents that make a right angle to the magnetic variation vectors. The point at $02: 59$ is circled. 
the magnetic pulsations (righthand side) at La Ronge for the first cycle of the oscillations. The observed drift velocity here are averaged over an area $\pm 100 \mathrm{~km}$ both in longitude and latitude centered at La Ronge. The deduced drift velocities are obtained in such a way that they are reversed vectors of the electric currents, which make a right angle to the observed magnetic variation vectors at La Ronge. This figure indicates the phase coincidence between the observed drifts and the deduced drifts. The phase relationship is more evident in Fig. 5. Here, the ordinate is the phase angle of the deduced drift velocity and the abscissa represents that of the observed drifts. This figure indicates that the phases of the two are coincident to a high degree.

The electric currents which produce magnetic field fluctuations observable on the ground (poloidal magnetic field) consist of two parts; i.e., the Hall current caused by the electrostatic electric field (corresponds to divergence-free drift) and the Pedersen current due to the inductive electric field (irrotational drift), both being current vortices in the ionosphere. The Hall current due to the electrostatic electric field is inverse to the drifts, whereas the Pedersen current due to the inductive electric field makes a right angle to the drifts. Thus, the phase coincidence between the

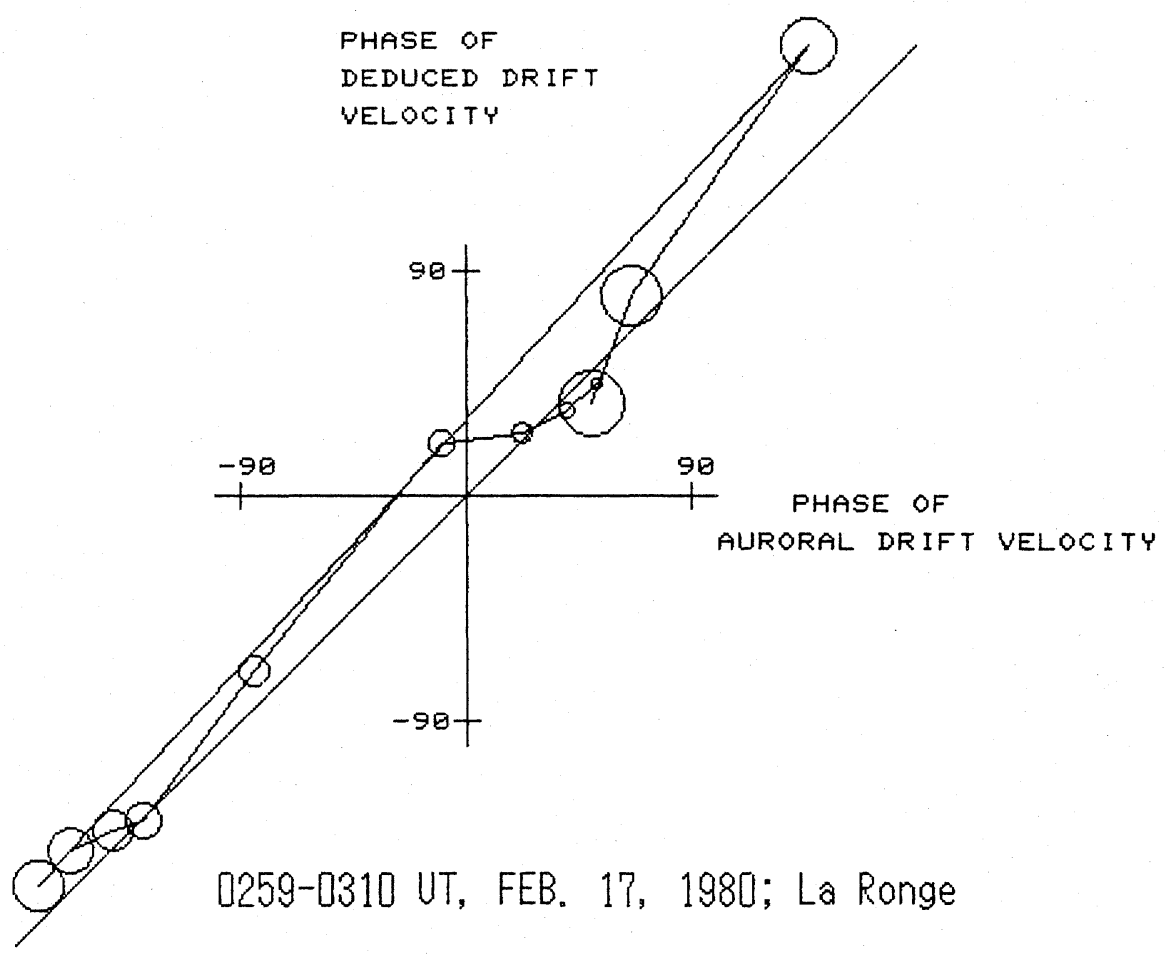

Fig. 5. Relationship between the phase angle of the observed drifts and that of the deduced drifts from 02:59 to 03:10 UT. The size of the circle at each point indicates the time sequence, i.e., from smaller to larger. 
observed drifts and those deduced from the magnetic variations in Fig. 5 indicates that the currents responsible for the ground magnetic variations below the ionosphere is the Hall current due to electrostatic electric field, and further that the relevant wave is predominantly shear Alfvenic. This is a reasonable conclusion because the period of the oscillation is so long, 10 minutes, and the oscillation is limited in a small latitude range as seen later in Fig. 6. An assumption here is that the inhomogeneity of the conductivity is negligibly small. This assumption is reasonable because the auroral patches here are extremely faint and, hence, no significant difference of ionization rate is expected to occur between the regions with and those without the auroral patches.

\section{Wave Characteristics Deduced from the Concurrent Magnetic Pulsations}

Since we have established the relationships between the drifts of auroral patches and concurrent magnetic pulsations in the previous section, we are now able to examine the wave characteristics, in a more extensive area, on the basis of magnetic variations.

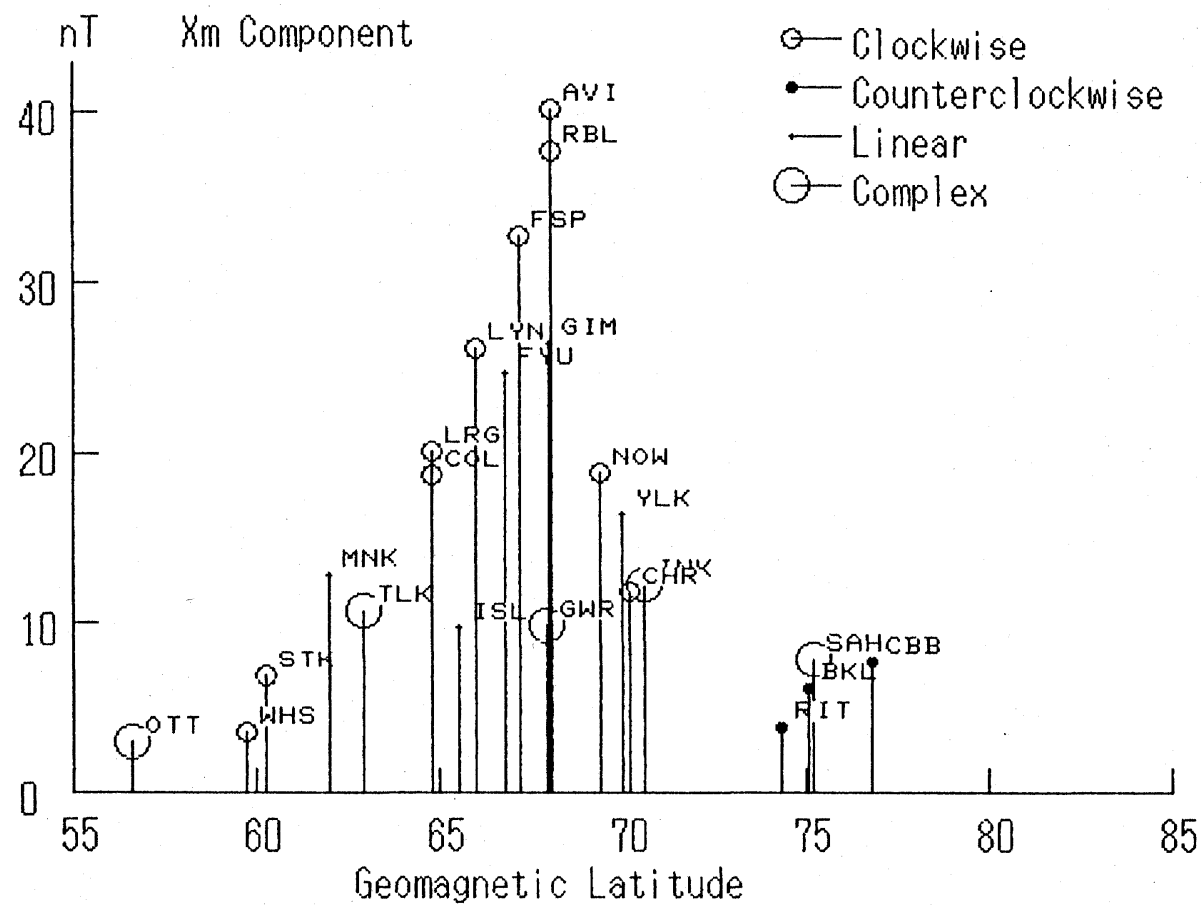

Fig. 6. Latitude profile of $X_{\mathrm{m}}$-component of the magnetic pulsations from 02:59 to 03:10 UT. Stations are in the Canada-Alaska area. 
The latitudinal distribution of the double amplitude of the concurrent magnetic pulsations in the Canada-Alaska area is shown in Fig. 6. The magnetic pulsations here are confined to a range in geomagnetic latitude, from $65^{\circ}$ to $73^{\circ}$, having the maximum at $67^{\circ}$ to $68^{\circ}$. Also shown here is the polarization of the pulsation. The polarization is clockwise in most of the area with linear and complex polarization at some stations. The clear counterclockwise rotation is seen only at 3 northernmost stations located around $75^{\circ}$ in geomagnetic latitude. The polarization sense is not reversed at the peak of the amplitude.

The temporal-spatial variations of the Hall currents (accurately inverse to the drifts as seen in the discussion in the previous section) are deduced from the magnetic pulsations in the Canada-Alaska area as shown in Fig. 7. As inferred from these figures, the iso-phase line is slant with the latitude circle similar to that of the drift distribution in Fig. 3. The pattern of the Hall currents also propagates from the dayside to the nightside and from the south to the north, similar to Fig. 3. This is in agreement with the result on the phase shift of Pc5 magnetic pulsations obtained by SAKA et al. (1983) in the evening sectors. The area where the drifts of auroral patches are measured (auroral patches are available), as seen in Figs. 3 and 7, covers the evening sector of the southern part of the area where the concurrent magnetic pulsations occur.

An important point here is that the longitudinal (azimuthal) phase speed, averaged from the Alaskan meridian to the Saskatchewan meridian, is much faster than that obtained by the auroral drifts in the Saskatchewan area (La Ronge). Figure 8 shows the $X_{\mathrm{m}}$-component of magnetic field changes from 3 selected stations, Arctic Village (AVI), Fort Simpson (FSP) and Rabbit Lake (RBL) along the $67^{\circ}-68^{\circ}$ geomagnetic latitude circle. The average phase speed in this longitude range is about $20 \mathrm{~km} / \mathrm{sec}$, equivalent to the azimuthal wave length of $12,000 \mathrm{~km}$. The longitudinal phase speed varies from $20 \mathrm{~km} / \mathrm{sec}$ in the dayside to $3-4 \mathrm{~km} / \mathrm{sec}$ in the evening sector. Consequently, the azimuthal wave number, when conventionally estimated within a small extent in longitude, is 1.2 in the dayside and increases to 7-8 in the evening sector. The azimuthal wave number of this oscillation is not constant in longitude but increases steeply from the dayside to the evening sector.

\section{Concurrent Magnetic Pulsations in Space}

The signature of these pulsations is a positive magnetic impulse overlapped with a slight tendency of pulsations in middle and low latitudes in the dayside. The $X_{\mathrm{m}}$-component at Memambetsu (MEM) is shown in Fig. 9 as an example. This fact suggests that these pulsations, as well as the impulse, are possibly excited by a sudden increase in the dynamic pressure of the solar wind. Unfortunately, the solar wind parameters were not available in the vicinity of the earth at the time. The possible validity of this idea, however, is supported by the solar wind measurement by ISEE-3 at $267.8 \mathrm{Re}$ upstream of the earth. A sudden increase overlapped with a slight tendency of oscillations in the dynamic pressure with a period of 14-15 minutes is found at 01:40 UT (Data Book, WDC-C2 for Geomagnetism, 1986). The sudden 

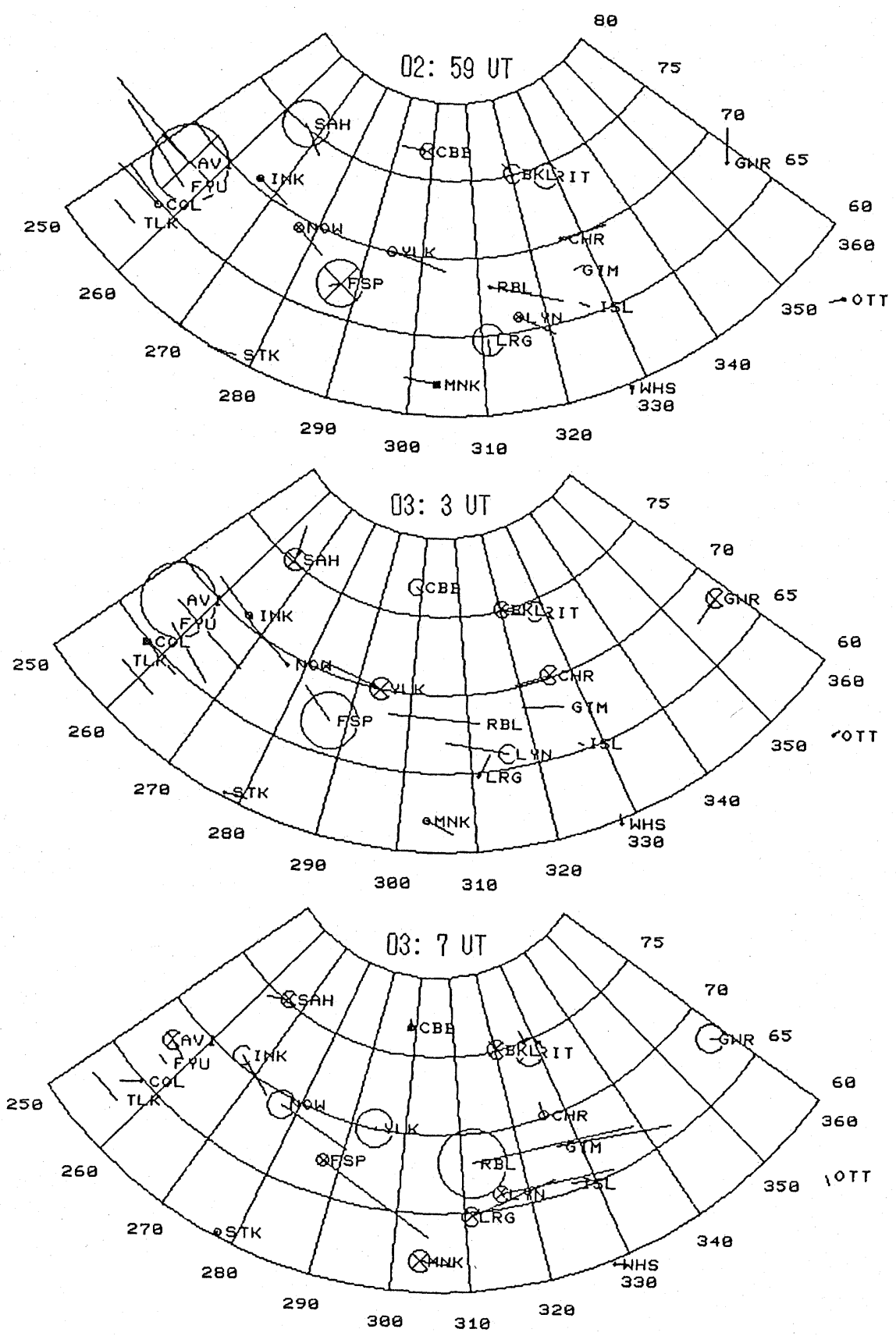

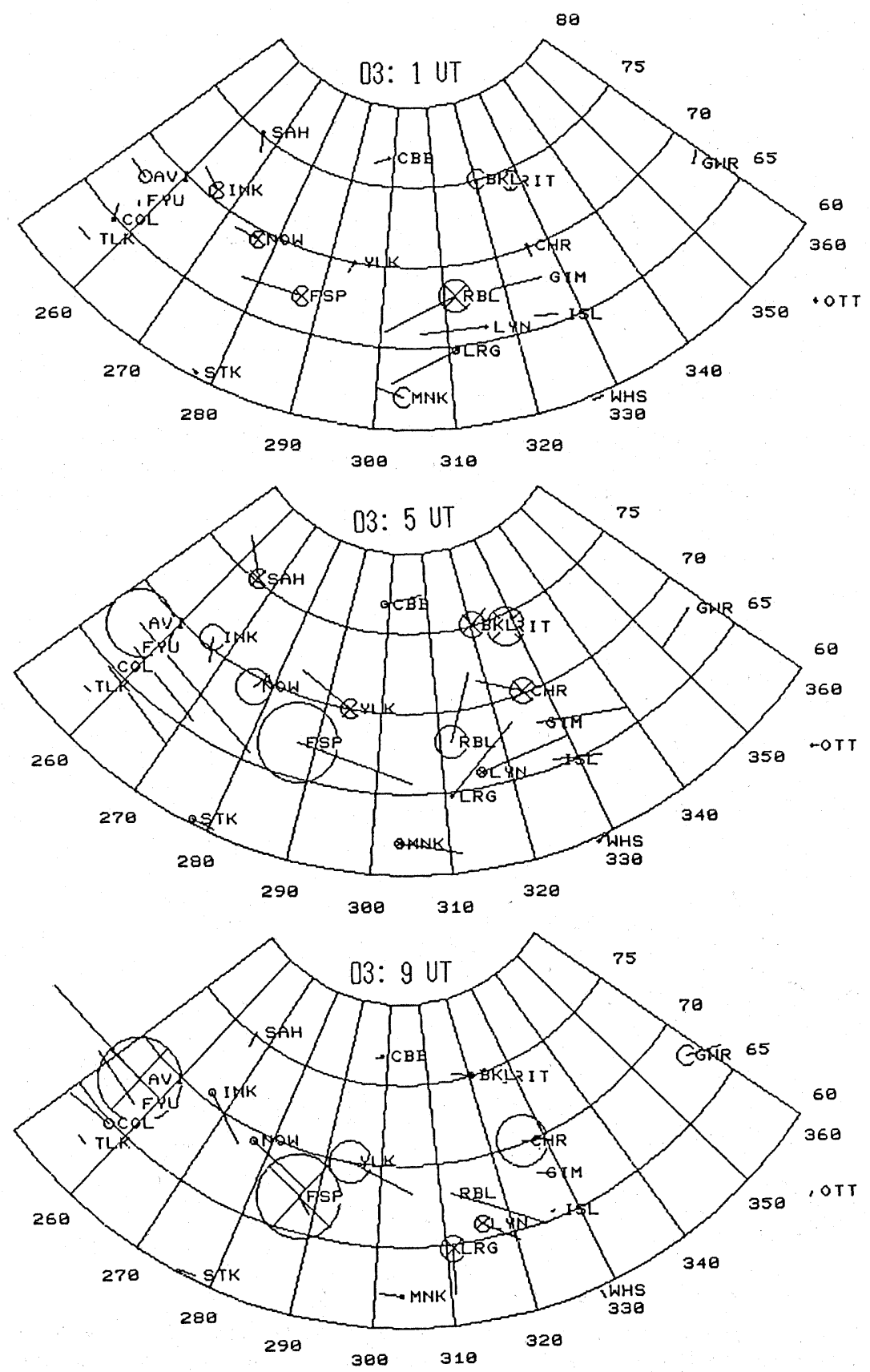

Fig. 7. Temporal-spatial variations of Hall currents deduced from magnetic pulsations from 02:59 to 03:10 UT in the Canada-Alaska area. The circle indicates the upward variation in $Z$ component (counterclockwise current vortex) and that with a cross indicates the downward (clockwise). The magnetic local time is approximately 19:00 at magnetic $310^{\circ}$ meridian. 


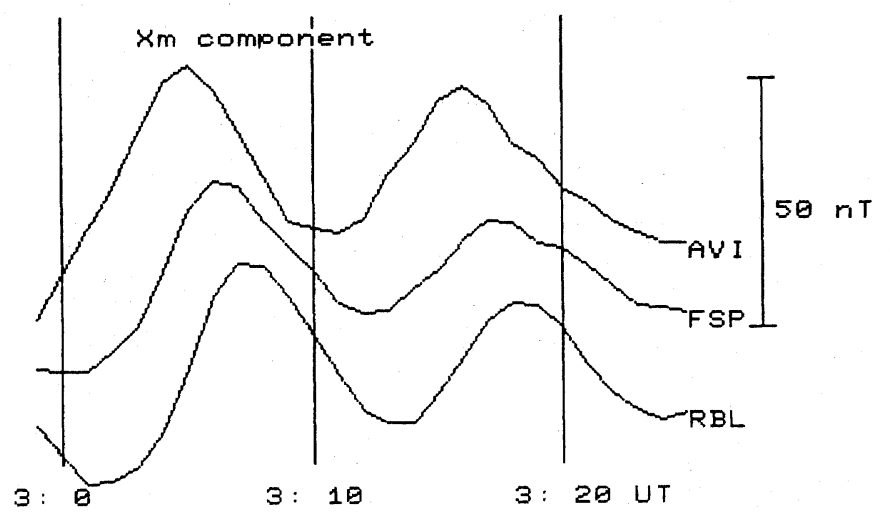

Fig. 8. $X_{\mathrm{m}}$-component from Arctic Village (AVI), Fort Simpson (FSP) and Rabbit Lake (RBL) along the $67^{\circ}-68^{\circ}$ latitude zone. The phase shift from the dayside (AVI) to the dusk (RBL) indicates an average velocity about $20 \mathrm{~km} / \mathrm{sec}$.

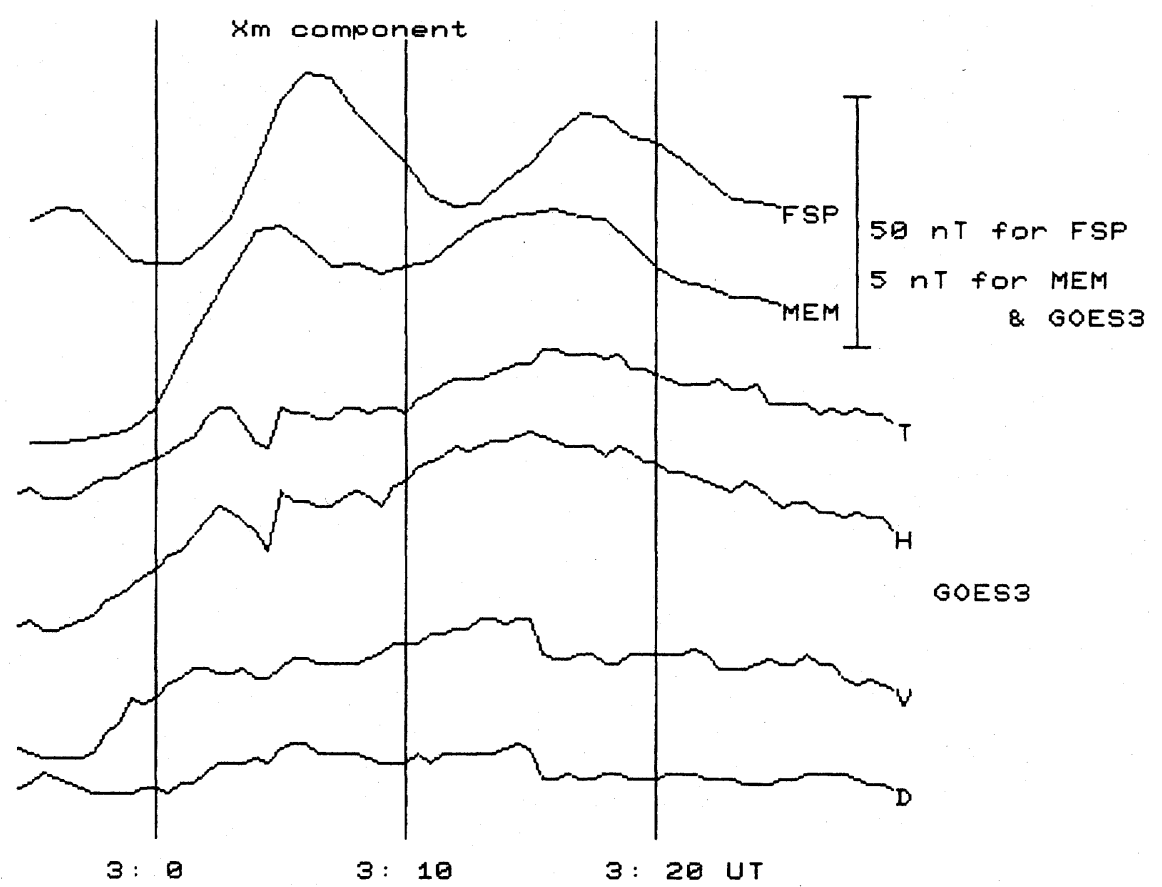

Fig. 9. $X_{\mathrm{m}}$-component from Fort Simpson (FSP) and Memambetsu (MEM) along with the Magnetic field variations at GOES-3. $T, H, V$ and $D$ are the magnetic total intensity, field component parallel to the dipole axis, radial outward component perpendicular to the dipole axis, and azimuthal eastward component, respectively. The negative spikes at 03:04 UT on $T$ and $H$ traces, as well as the negative steps at 03:15 UT on $V$ and $D$ traces, are due to artificial noises. 
increase in the dynamic pressure at ISEE-3 leads the magnetic impulse and the pulsations on the ground by 80 minutes. This is consistent with the time for the pressure change in the solar wind to arrive at the magnetosphere with the observed speed of $370 \mathrm{~km} / \mathrm{sec}$.

During the course of the drift oscillations associated with the magnetic pulsations, small variations in magnetic fields are found at synchronous GOES-3 satellite approximately conjugate with Fort Simpson (FSP). The relation between magnetic variations at Fort Simpson (FSP), Memambetsu (MEM) and GOES-3 are shown in Fig. 9. The magnetic field changes at GOES-3 are mainly compressional, about $2 \mathrm{nT}$, as seen by the changes in total intensity $(T)$, and $H$ and $V$ components. The north-south magnetic field variation at the ground conjugate area (Fort Simpson) follows the compressional variation at GOES-3 with a phase lag larger than $90^{\circ}$. The maximum compression at GOES-3 in the magnetospheric equatorial region is coincident with the change in the conjugate ground magnetic field (FSP) from southward to northward. This corresponds to the change in the electric field from southward to northward and the change in the drift from eastward to westward.

\section{Conclusion and Discussion}

The latitude-time expression of the drift of auroral patches studied in this paper are in agreement with those obtained by WALKER et al. (1979) from the drift measurements by STARE radar at concurrent Pc5 magnetic pulsations. A close examination of the phase relationships between magnetic and drift oscillations in this study further shows that the magnetic pulsations here are essentially produced by the Hall currents, due to electrostatic electric fields, which are brought forth from shear Alfven waves. This study, therefore, indicates that the measurement of the drifts of auroral patches are a convenient method to relate the magnetic pulsations to the concurrent electric field fluctuations, and, subsequently, to determine the nature of the magnetospheric source of ground magnetic pulsations.

The poleward phase shift, such as seen in Fig. 3, is usually understood in terms of the field-line resonance proposed by SOUTHWOOD (1974) and CHEN and HASEGAWA (1974). However, this study shows that the longitudinal phase speed, and subsequently the azimuthal wave length are much larger in the dayside, and they decreases steeply from dayside to the evening sector in contrast to the assumptions in their model; i.e., the longitudinal uniformity and quite large wave number. In addition, the polarization sense is not reversed at the peak region of the oscillation amplitude. These results indicate that their excitation model is not directly applied to this particular oscillation. At least, the strong longitudinal non-uniformity of the oscillation must be taken into consideration in the oscillation model. Further examination of the wave properties will be necessary in reaching a model that explains the oscillations where an azimuthal non-uniformity is significant as this example.

The magnetic field changes at synchronous orbit in relation to those on the ground in Fig. 9 implies that, in the duskside magnetosphere, the eastward (antisunward) plasma flow first occurs, then the compression reaches maximum there 
followed by the sunward flow afterwards. The shear Alfven mode (whether resonant or not), which is related to the electrostatic electric field, is likely coupled with and excited by the moving (towards nightside) compressional variations in the outer magnetosphere, possibly connected with the flow of the high pressure region in the solar wind outside. It is difficult to explain this oscillation in terms of the $K-H$ instability because its amplitude is larger in the dayside where the velocity shear must be small, and its azimuthal wave length is much longer than that expected.

Although the change in the patch luminosity is out of scope of this paper, it may be worthnoting that the luminosity does not as significantly increase at the time of oscillations (sudden impulse in low latitudes) as that of pulsating auroras. The compression about $2 \mathrm{nT}$ observed at GOES-3 appears to be ineffective on the enhancement in electron precipitation. This may call in question about the effectiveness of the CORONITI-KENNEL (1970) mechanism in explaining the modulation of electron precipitation fluxes.

\section{REFERENCES}

Chen, L. and A. Hasegawa, A theory of long-period magnetic pulsations, 1. Steady state excitation of field line resonance, J. Geophys. Res., 79, 1024-1032, 1974.

Coroniti, F. V. and C. F. Kennel, Electron precipitation pulsations, J. Geophys. Res., 75, 1279-1289, 1970.

Johnstone, A. D., The mechanism of pulsating aurora, Ann. Geophys. Gauthier-Villars, 1, 397-410, 1983.

MCEwen, D. J. and C. N. DunCAN, A campaign to study pulsating auroras, Can. J. Phys., 59, 1029-1033, 1981.

Nakamura, R. and T. Oguti, Drifts of auroral structures and magnetospheric electric fields, J. Geophys. Res., 92, 1987 (in press).

OGuTI, T., Recurrent auroral patterns, J. Geophys. Res., 81, 1782-1786, 1976.

OGuti, T., TV observations of auroral arcs, Physics of Auroral Arc Formation, Geophy. Monograph Ser., A.G.U., 25, 31-41, 1981.

OGUTI, T., Relationships between auroral and concurrent geomagnetic pulsations, J. Geomag. Geoelectr., 38, 837-859, 1986.

Oguti, T. and K. HAYASHI, Multiple correlations between auroral and magnetic pulsations, 2. Determination of electric currents and electric fields around a pulsating auroral patch, J. Geophys. Res., 89, 7467-7481, 1984.

OGUTI, T. and K. HAYASHI, Polarization and wave form of magnetic pulsations below pulsating auroras: Magnetic effects of electric currents induced in an ionization tail of a moving auroral patch, $J$. Geomag. Geoelectr., 37, 65-91, 1985.

SAKA, O., J. S. KIM, and M. SugiURA, Comparison of phase and amplitude structures of Pc5 pulsations in the morning and afternoon sectors, J. Geophys. Res., 88, 881-888, 1983.

Scourfield, M. W. J., J. G. KeYs, E. Nielsen, and C. K. Goertz, Evidence for the $\boldsymbol{E} \times \boldsymbol{B}$ Drift of pulsating auroras, J. Geophys. Res., 88, 7983-7988, 1983.

Southwood, D. J., Some features of field line resonances in the magnetosphere, Planet. Space Sci., 22, 483-491, 1974.

VIllain, J. P., Characteristics of Pc5 micropulsations as determined with the STARE experiment, $J$. Geophys. Res., 87, 129-137, 1982.

Walker, A. D. M., R. A. Greenwald, W. F. Stuart, and C. A. Green, Stare auroral radar observations of Pc5 geomagnetic pulsations, J. Geophys. Res., 84, 3373-3388, 1979.

Data Book, WDC-C2 for geomagnetism, Special Issue (ISEE-3, $A E, D_{\text {st }}, K_{\mathrm{p}}$ ), August, 1986. 